\title{
Comparison of one anastomosis gastric bypass versus standard Roux-en-Y gastric bypass versus a variant of biliopancreatic diversion, in a case-matched, non-superobese population: 6 years of follow-up
}

\author{
George Markopoulos, George Skroubis, Fotis Kalfarentzos, loannis Kehagias \\ Department of Surgery, Division of Bariatric and Metabolic Surgery, General University Hospital of Patras, Patras, Greece
}

Gastroenterology Rev 2022; 17 (2): 152-161

DOI: https://doi.org/10.5114/pg.2021.108453

Key words: gastric bypass, biliopancreatic diversion, metabolic deficiencies.

Address for correspondence: Prof. loannis Kehagias, Department of Surgery, Division of Bariatric and Metabolic Surgery, General University Hospital of Patras, Patras, Greece, phone: +30 6977343248, e-mail: ikehag@yahoo.gr

\begin{abstract}
Introduction: One anastomosis gastric bypass (OAGB) is gaining increasing acceptance as a simple, safe, and effective operation for treating morbid obesity. Data comparing this procedure with the most effective biliopancreatic diversions (BPD) remain scarce, and most studies evaluate OAGB against standard Roux-en-Y gastric bypass (RYGB).

Aim: To present the mid-term results of a comparison of RYGB, OAGB, and our modification of BPD in an exclusively non-superobese population, regarding safety, efficacy, preservation of weight loss, as well as late postoperative metabolic and non-metabolic complications.

Material and methods: From our cohorts of patients treated for morbid obesity with OAGB, RYGB, and BPD at Patras University Hospital, we identified patients who had case-matched preoperative profiles regarding age, preoperative body mass index (BMI), and obesity-related comorbidities (diabetes mellitus, hypertension, and dyslipidaemia). Thirty-four patients from each group were included in the study. Bariatric outcomes, non-metabolic complications, and postoperative metabolic parameters were followed until the $6^{\text {th }}$ postoperative year.

Results: The average patient age was 37.4 years (range: 19-57), $85.3 \%$ were female and $14.7 \%$ were male, with a mean BMI of $46.3 \mathrm{~kg} / \mathrm{m}^{2}$ (range: 38.3-49.7). Regarding weight loss and glycaemic control, OAGB had comparable results to BPD and was significantly better than RYGB. The safety profile was analogous to RYGB, with the exception of calcium levels, which, even though they were within normal range, were significantly lower than those in RYGB. Comorbidities were successfully treated with all operations at comparable rates. In this cohort, no other major complications were observed.

Conclusions: OAGB offered mid-term results comparable to BPD while being safe and with minimal impact on the patient's nutritional state. It is an effective procedure for treating morbid obesity, which results in sustained weight loss and a high rate of resolution of comorbidities.
\end{abstract}

\section{Introduction}

A surgical approach remains the only effective treatment concerning the long-term management of morbid obesity [1]. During the evolution of bariatric surgery, many procedures have been described, having different mechanisms of action. These mechanisms are defined in general as restrictive, malabsorptive, or a combination of both [2].

Standard Roux-en-Y gastric bypass (RYGB), which is considered the gold standard of bariatric operations, achieves weight loss mainly through the limitation of food intake, the dumping effect, and also due to hormonal changes affecting appetite [3, 4].

One anastomosis gastric bypass (OAGB, mini gastric bypass - MGB) was first described by Rutledge in 1997 and reported in 2001 [5]. It has approximately 25\% increased weight loss efficacy in comparison to RYGB, deriving from the malabsorptive effect of its much longer biliopancreatic limb [6]. It is gaining increasing acceptance as a simple, safe, and effective operation for the treatment of morbid obesity, with several series published from all over the world, and it is now recog- 
nized by the International Federation for the Surgery of Obesity and Metabolic Disorders (IFSO) as a mainstream bariatric procedure [7].

Biliopancreatic diversions (BPD), in addition to all the aforementioned mechanisms, cause weight loss primarily through the malabsorption of fats and complex carbohydrates. Due to this dual mechanism of action, biliopancreatic diversions are regarded as the most effective type of bariatric operations, with optimal long-term results [8]. They were shown to provide the greatest and most sustainable weight loss and had the most powerful effect in controlling blood glucose levels and lipid levels [9].

However, all types of operations exclude parts of the gastrointestinal (GI) tract from alimentation, resulting in potential development of metabolic deficiencies, such as those of certain minerals, vitamins, and protein malnutrition $[10,11]$.

\section{Aim}

The aim of this study is to present the mid-term results of a comparison of RYGB, OAGB, and our modification of BPD in an exclusively non-superobese population, regarding safety, efficacy, preservation of weight loss, as well as late postoperative metabolic and non-metabolic complications.

\section{Material and methods}

The Morbid Obesity Unit in our hospital was established in June 1994. As of September 2018, 2370 morbidly obese patients have undergone various bariatric procedures, including different types of malabsorptive operations. We have standardized our variant of biliopancreatic diversion (BPD-LL, biliopancreatic diversion with Roux-en-Y gastric bypass and long limbs), which proved to be both safe and effective [12-14]. Since 2012, OAGB has also been offered to our patients.

A cohort of case-matched morbidly obese patients (body mass index (BMI) $35-50 \mathrm{~kg} / \mathrm{m}^{2}$ ) who had undergone RYGB, OAGB, or BPD-LL in our unit was identified. Case matching was performed on the basis of patients' age, preoperative BMI, and the presence of obesity-related comorbidities (diabetes mellitus, hypertension, and dyslipidaemia), resulting in 3 groups of 34 patients, for a total of 102 . We retrospectively analysed prospectively collected data of this cohort for a follow-up period of 6 years. The analysis included the patients' preoperative clinical characteristics, postoperative morbidity and mortality, nutritional and metabolic deficiencies, resolution of comorbidities, and weight loss assessments. The 3 groups were adequately matched (Tables I and II).

All patients were scheduled to undergo a complete follow-up, including clinical, nutritional, and laboratory
Table I. Demographic parameters in matching

\begin{tabular}{|c|c|c|c|}
\hline Parameter & RYGB & OAGB & BPD-LL \\
\hline Male & $5(14.7 \%)$ & 5 & 5 \\
\hline Female & $29(85.3 \%)$ & 29 & 29 \\
\hline Age & $\begin{array}{c}37.7 \\
(19-57)\end{array}$ & $\begin{array}{c}38.3 \\
(20-57)^{*}, \text { ns }\end{array}$ & $\begin{array}{c}36.1 \\
(19-56)^{* *}, \mathrm{~ns}\end{array}$ \\
\hline Age, SD & 9.5 & 9.6 & 10.2 \\
\hline Baseline BMI & $\begin{array}{c}46.1 \\
(41.3-49.1) \\
\end{array}$ & $\begin{array}{c}46.2 \\
(41.0-49.6)^{+, n s}\end{array}$ & $\begin{array}{c}46.7 \\
(38.3-49.7)^{++, n s}\end{array}$ \\
\hline Baseline BMI, SD & 1.7 & 2.3 & 2.4 \\
\hline Diabetes & $6(17.6 \%)$ & $6(17.6 \%)$ & 6 (17.6\%) \\
\hline Dyslipidaemia & $12(35.3 \%)$ & $11(32.4 \%)$ & $12(35.3 \%)$ \\
\hline Hypertension & $10(29.4 \%)$ & $7(20.6 \%)$ & $7(20.6 \%)$ \\
\hline
\end{tabular}

${ }^{*} p=0.368,{ }^{* *} p=0.801,{ }^{+} p=0.385,{ }^{++} p=0.798$.

Table II. Preoperative metabolic and nutritional parameters

\begin{tabular}{|c|c|c|c|c|c|}
\hline \multirow[t]{2}{*}{ Parameter } & \multicolumn{3}{|c|}{ Mean values } & \multicolumn{2}{|c|}{$P$-value } \\
\hline & RYGB & OAGB & BPD-LL & $\begin{array}{l}\text { OAGB } \\
\text { vs. } \\
\text { RYGB }\end{array}$ & $\begin{array}{c}\text { OAGB } \\
\text { vs. } \\
\text { BPD-LL }\end{array}$ \\
\hline $\mathrm{Ht}$ & 40.6 & 40.5 & 40.5 & 0.865 & 0.954 \\
\hline $\mathrm{Hb}$ & 13.4 & 13.2 & 13.3 & 0.542 & 0.659 \\
\hline Glc & 102.5 & 106.4 & 106.6 & 0.578 & 0.984 \\
\hline Ur & 29.7 & 33.5 & 31.4 & 0.109 & 0.381 \\
\hline $\mathrm{Cr}$ & 0.8 & 1.0 & 0.8 & 0.280 & 0.217 \\
\hline $\mathrm{Na}$ & 140.7 & 140.3 & 140.3 & 0.552 & 0.979 \\
\hline K & 4.4 & 4.4 & 4.3 & 0.732 & 0.343 \\
\hline $\mathrm{Ca}$ & 9.3 & 9.6 & 9.2 & 0.134 & 0.051 \\
\hline $\mathrm{Mg}$ & 2.0 & 2.1 & 2.1 & 0.276 & 0.854 \\
\hline$P$ & 3.5 & 3.7 & 3.6 & 0.503 & 0.725 \\
\hline TP & 7.3 & 7.2 & 7.2 & 0.440 & 0.956 \\
\hline Alb & 4.2 & 4.2 & 4.2 & 0.998 & 0.799 \\
\hline Uric & 5.6 & 5.5 & 5.1 & 0.676 & 0.218 \\
\hline TCHOL & 197.5 & 186.4 & 187.9 & 0.227 & 0.860 \\
\hline LDL & 121.6 & 111.8 & 113.4 & 0.178 & 0.815 \\
\hline $\mathrm{HDL}$ & 45.2 & 48.8 & 47.0 & 0.256 & 0.515 \\
\hline Tgl & 143.2 & 129.3 & 137.4 & 0.599 & 0.747 \\
\hline $\mathrm{Fe}$ & 74.0 & 68.9 & 71.9 & 0.428 & 0.620 \\
\hline Ferritin & 62.8 & 86.1 & 54.7 & 0.388 & 0.254 \\
\hline Folic & 6.9 & 5.7 & 6.4 & 0.073 & 0.251 \\
\hline $\mathrm{B}_{12}$ & 374.7 & 371.6 & 514.2 & 0.914 & 0.313 \\
\hline PTH & 44.0 & 56.4 & 42.8 & 0.127 & 0.059 \\
\hline $\mathrm{HbA}_{1 \mathrm{c}}$ & 5.7 & 6.0 & 5.8 & 0.145 & 0.349 \\
\hline
\end{tabular}




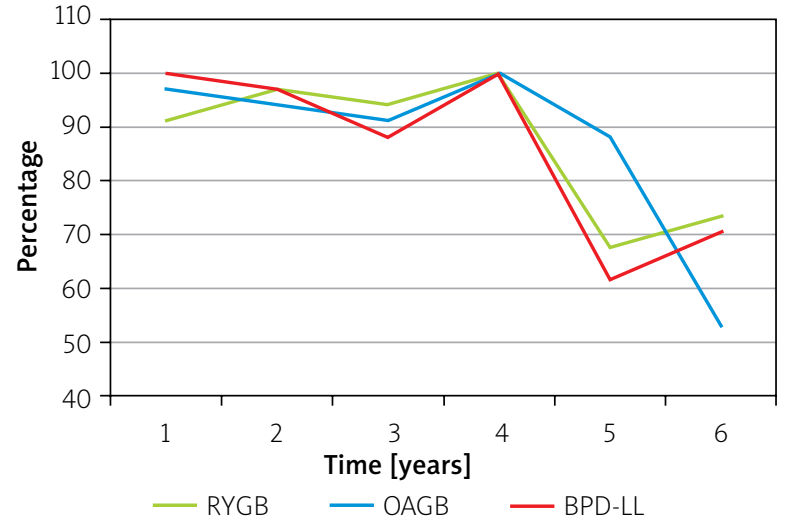

Figure 1. Follow-up rates during the study

evaluation preoperatively and on the $1^{\text {st }}, 3^{\text {rd }}, 6^{\text {th }}$, and $12^{\text {th }}$ month postoperatively and every year thereafter. The follow-up was performed by the same medical and nutritional team, and biochemical and nutritional parameters were strictly measured in the same laboratory. A bariatric procedure was considered successful if the percentage of excess weight loss (EWL\%) was above $50 \%$ and BMI was below $35 \mathrm{~kg} / \mathrm{m}^{2}$. After surgery, all patients received a daily multivitamin and mineral supplement, including oral calcium and vitamin $D_{3}(1000 \mathrm{mg}$ calcium carbonate $+800 \mathrm{IU}$ vitamin $\mathrm{D}_{3}$ daily). Premenopausal women were also prescribed oral iron supplementation. All patients were prescribed protein pump inhibitors for a period of 6 months and antithrombotic medication with low molecular weight heparin (LMWH) for the first post-operative month.

\section{Surgical procedures}

RYGB consisted of a gastric pouch of $15 \pm 5 \mathrm{ml}$, an alimentary limb of $150 \mathrm{~cm}$, a biliopancreatic limb of $50 \mathrm{~cm}$, and a gastrointestinal anastomosis of $1.5 \mathrm{~cm}$ internal diameter.

OAGB was created with a long and narrow gastric pouch, with the first horizontal 45-mm linear stapler firing at the incisura angularis level. The length of the bypassed biliopancreatic limb was $250 \mathrm{~cm}$, providing that the common channel was at least $300 \mathrm{~cm}$, which was the case for all the patients in this cohort.

Our variant of biliopancreatic diversion (BPD-LL) involved a gastric pouch of $40 \pm 10 \mathrm{ml}$ with complete separation from the bypassed stomach, an alimentary limb of $400 \mathrm{~cm}$, a common channel of $100 \mathrm{~cm}$, with the rest of the bowel being the biliopancreatic limb. In the case of an intestinal length shorter than $500 \mathrm{~cm}$, the common channel remained $100 \mathrm{~cm}$ and other 2 limbs were constructed shorter, with the alimentary limb at $250 \mathrm{~cm}$.

\section{Statistical analysis}

All values are expressed as a mean \pm standard deviation, unless otherwise stated. The mean values of all parameters were compared using Student's $t$ test. All reported $p$-values are 2 -sided and significant at a level of $p \leq 0.05$.

\section{Results}

All studied patients had reached their sixth postoperative year. There was a consistent $88-100 \%$ follow-up rate up until the fourth postoperative year, while approximately $73.5 \%, 52.9 \%$, and $70.6 \%$ of patients who underwent RYGB, OAGB, and BPD-LL, respectively, were evaluated at the 6-year follow-up visit (Figure 1).

\section{Mortality and late non-metabolic morbidity}

No deaths or major non-metabolic complications were recorded during the 6-year follow-up period of this cohort.

\section{Metabolic deficiencies}

All patients received postoperatively the same nutritional supplements and had similar compliance to the medication ( $85 \%)$.

No differences were observed regarding renal function, most electrolytes ( $\mathrm{Na}, \mathrm{K}, \mathrm{Mg}), \mathrm{B}_{12}$, and metabolism.

\section{Folic acid}

The mean folic acid levels for patients who received RYGB were $7.9 \mathrm{ng} / \mathrm{ml}$ at 1 year, $8.2 \mathrm{ng} / \mathrm{ml}$ at 2 years, $8.7 \mathrm{ng} / \mathrm{ml}$ at 3 years, $9.4 \mathrm{ng} / \mathrm{ml}$ at 4 years, $12.1 \mathrm{ng} / \mathrm{ml}$ at 5 years, and $10.4 \mathrm{ng} / \mathrm{ml}$ at 6 years. The mean folic acid levels for patients who received OAGB were $7.3 \mathrm{ng} / \mathrm{ml}$ at 1 year, $8.5 \mathrm{ng} / \mathrm{ml}$ at 2 years, $6.9 \mathrm{ng} / \mathrm{ml}$ at 3 years, $7.2 \mathrm{ng} / \mathrm{ml}$ at 4 years, $8.6 \mathrm{ng} / \mathrm{ml}$ at 5 years, and $9.5 \mathrm{ng} / \mathrm{ml}$ at 6 years. The mean folic acid levels for patients who received BPD-LL were $12.1 \mathrm{ng} / \mathrm{ml}$ at 1 year, $13.5 \mathrm{ng} / \mathrm{ml}$ at 2 years, $13.2 \mathrm{ng} / \mathrm{ml}$ at 3 years, $14.3 \mathrm{ng} / \mathrm{ml}$ at 4 years, $13.4 \mathrm{ng} / \mathrm{ml}$ at 5 years, and $14.5 \mathrm{ng} / \mathrm{ml}$ at 6 years. The folic acid levels in the BPD-LL group were significantly higher than those of the other 2 groups at every year of the follow-up $(p<0.02)$, while there was no significant difference between patients of the RYGB and OAGB groups at any year.

\section{Bone metabolism}

The mean calcium levels for patients who received RYGB were $9.3 \mathrm{mg} / \mathrm{dl}$ preoperatively and $9.9 \mathrm{mg} / \mathrm{dl}$ at 1 year, $9.7 \mathrm{mg} / \mathrm{dl}$ at 2 years, $9.7 \mathrm{mg} / \mathrm{dl}$ at 3 years, $9.6 \mathrm{mg} / \mathrm{dl}$ at 4 years, $9.5 \mathrm{mg} / \mathrm{dl}$ at 5 years, and $9.3 \mathrm{mg} / \mathrm{dl}$ at 6 years. The mean calcium levels for patients who 
received OAGB were $9.6 \mathrm{mg} / \mathrm{dl}$ preoperatively and $9.5 \mathrm{mg} / \mathrm{dl}$ at 1 year, $9.2 \mathrm{mg} / \mathrm{dl}$ at 2 years, $9.2 \mathrm{mg} / \mathrm{dl}$ at 3 years, $9.0 \mathrm{mg} / \mathrm{dl}$ at 4 years, $9.0 \mathrm{mg} / \mathrm{dl}$ at 5 years, and $9.0 \mathrm{mg} / \mathrm{dl}$ at 6 years. The mean calcium levels for patients who received BPD-LL were $9.2 \mathrm{mg} / \mathrm{dl}$ preoperatively and $9.6 \mathrm{mg} / \mathrm{dl}$ at 1 year, $9.7 \mathrm{mg} / \mathrm{dl}$ at 2 years, $9.4 \mathrm{mg} / \mathrm{dl}$ at 3 years, $9.1 \mathrm{mg} / \mathrm{dl}$ at 4 years, $9.3 \mathrm{mg} / \mathrm{dl}$ at 5 years, and $9.0 \mathrm{mg} / \mathrm{dl}$ at 6 years. With sufficient postoperative calcium and vitamin $D_{3}$ supplementation, RYGB patients may have even better calcium levels than they had preoperatively. The same doses are insufficient for more malabsorptive procedures. Patients in the OAGB group had consistently statistically significant lower calcium levels $(p<0.01)$ and more cases of hypocalcaemia ( $23.5 \%$ vs. $8.8 \%$, respectively) than patients in the RYGB group. Moreover, OAGB patients had significantly lower calcium levels in the long term compared to BPD-LL, even though the mean values remained within the normal range (Figure 2).

Despite routine calcium and vitamin $\mathrm{D}_{3}$ supplementation, mean levels of PTH increased from their baseline for all bariatric procedures, but they remained also within the normal range (Figure 3). Secondary hyperparathyroidism (SHPT), defined as parathormon (PTH) $>65 \mathrm{mg} / \mathrm{ml}$, was present preoperatively in $14.7 \%$ of patients in the RYGB and BPD-LL groups and in $21.9 \%$ of patients in the OAGB group. The prevalence of SHPT decreased in the RYGB and BPD-LL groups for the first 2 postoperative years; for OAGB a decrease was observed only in the first postoperative year. Subsequently, there was a gradual increase for all 3 groups, reaching as much as $68 \%$ for OAGB at the sixth year of follow-up. The deference was constantly significant $(p<0.01)$ only between OAGB and the other 2 groups, even though BPD-LL is a more malabsorptive procedure than RYGB.

Mean levels of phosphorus and alkaline phosphatase (ALP) remained primarily within the normal range throughout the study. Hypophosphataemia was quite uncommon.

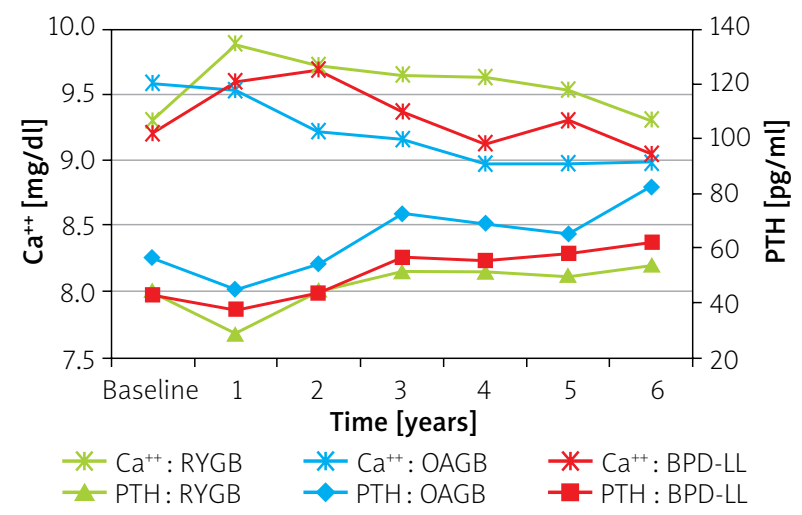

Figure 2. $\mathrm{Ca}^{++}$and PTH levels

\section{Anaemia}

The mean haemoglobin $(\mathrm{Hb})$ levels for female patients who received RYGB were $13.1 \mathrm{~g} / \mathrm{dl}$ preoperatively, $13.0 \mathrm{~g} / \mathrm{dl}$ at 1 year, $12.8 \mathrm{~g} / \mathrm{dl}$ at 2 years, $12.6 \mathrm{~g} / \mathrm{dl}$ at 3 years, $12.3 \mathrm{~g} / \mathrm{dl}$ at 4 years, $13.0 \mathrm{~g} / \mathrm{dl}$ at 5 years, and $12.5 \mathrm{~g} / \mathrm{dl}$ at 6 years. The mean haemoglobin levels for female patients who received OAGB were $12.9 \mathrm{~g} / \mathrm{dl}$ preoperatively, $12.6 \mathrm{~g} / \mathrm{dl}$ at 1 year, $11.9 \mathrm{~g} / \mathrm{dl}$ at 2 years, $11.9 \mathrm{~g} / \mathrm{dl}$ at 3 years, $11.6 \mathrm{~g} / \mathrm{dl}$ at 4 years, $11.9 \mathrm{~g} / \mathrm{dl}$ at 5 years, and $11.8 \mathrm{~g} / \mathrm{dl}$ at 6 years. The mean haemoglobin levels for female patients who received BPD$\mathrm{LL}$ were $13.0 \mathrm{~g} / \mathrm{dl}$ preoperatively, $12.5 \mathrm{~g} / \mathrm{dl}$ at 1 year, $12.2 \mathrm{~g} / \mathrm{dl}$ at 2 years, $11.8 \mathrm{~g} / \mathrm{dl}$ at 3 years, $11.3 \mathrm{~g} / \mathrm{dl}$ at 4 years, $11.7 \mathrm{~g} / \mathrm{dl}$ at 5 years, and $11.5 \mathrm{~g} / \mathrm{dl}$ at 6 years. There were no statistically significant differences between the groups at any time of the follow-up.

However, the range of $\mathrm{Hb}$ levels within each group was consistently high. As a result, anaemia - as defined as $\mathrm{Hb}<12 \mathrm{~g} / \mathrm{dl}$ - was present preoperatively in $17.2 \%$ of women in the RYGB and OAGB groups and in $13.8 \%$ in the BPD-LL group. The prevalence of anaemia for the RGYB group reached $14.8 \%$ at 1 year, $25 \%$ at 2 years, $25.9 \%$ at 3 years, $34.5 \%$ at 4 years, $19 \%$ at 5 years, and $39.1 \%$ at 6 years. For the OAGB group the prevalence was $28.6 \%$ at 1 year, $44.4 \%$ at 2 years, $42.3 \%$ at 3 years, $55.2 \%$ at 4 years, $45.8 \%$ at 5 years, and $53.3 \%$ at 6 years, while for the BPD-LL group it was $31 \%$ at 1 year, $39.3 \%$ at 2 years, $56 \%$ at 3 years, $55.2 \%$ at 4 years, $52.9 \%$ at 5 years, and $57.9 \%$ at 6 years (Figure 4 ). These differences were significant $(p<0.05)$ for the first 5 years of the follow-up between RYBG and the other 2 groups. There was 1 case in each of the OAGB and BPD-LL groups that required administration of intravenous iron.

The small number of men in the cohort is a serious limitation in assessing the anaemia incidence and significance in this subgroup, because there is only 1 patient difference in the cohort's variability.

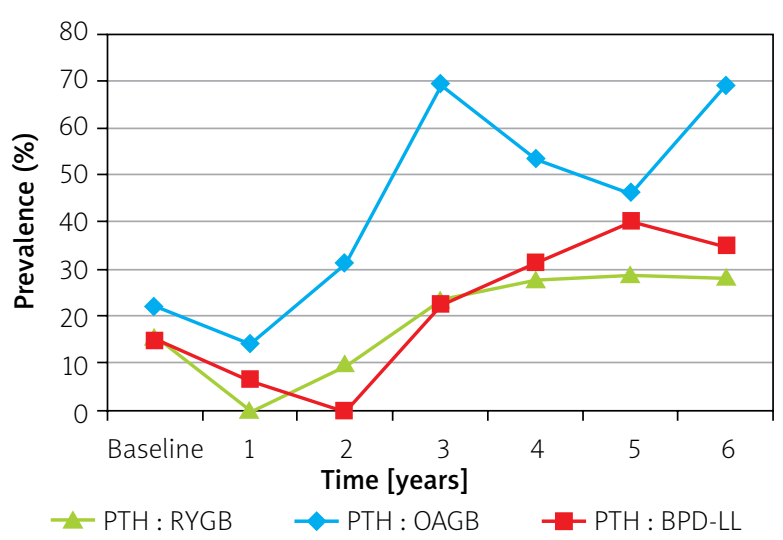

Figure 3. Secondary hyperparathyroidism 


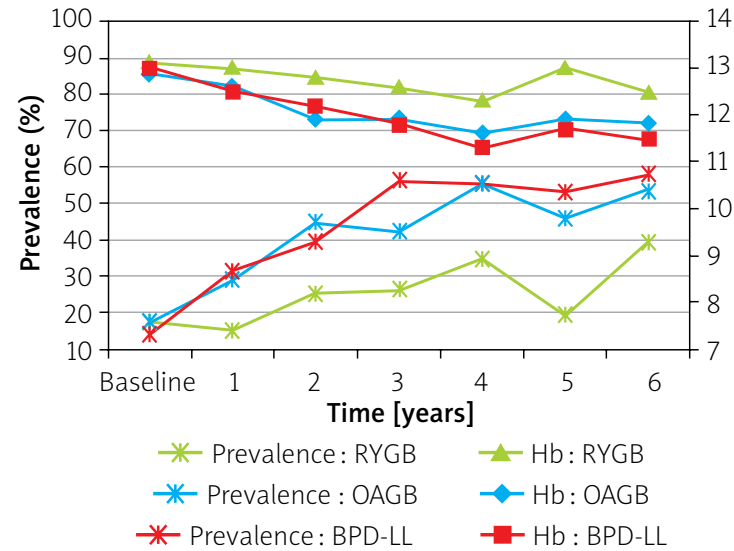

Figure 4. Haemoglobin levels and anaemia $(\mathrm{Hb}$ $<12 \mathrm{~g} / \mathrm{dl}$ ) prevalence in women

\section{Hypoalbuminaemia}

The mean albumin levels for patients who received RYGB were $4.5 \mathrm{~g} / \mathrm{dl}$ at 1 year, $4.4 \mathrm{~g} / \mathrm{dl}$ at 2 years, $4.5 \mathrm{~g} / \mathrm{dl}$ at 3 years, $4.4 \mathrm{~g} / \mathrm{dl}$ at 4 years, $4.4 \mathrm{~g} / \mathrm{dl}$ at 5 years, and $4.2 \mathrm{~g} / \mathrm{dl}$ at 6 years. The mean albumin levels for patients who received OAGB were $4.4 \mathrm{~g} / \mathrm{dl}$ at 1 year, $4.3 \mathrm{~g} / \mathrm{dl}$ at 2 years, $4.3 \mathrm{~g} / \mathrm{dl}$ at 3 years, $4.3 \mathrm{~g} / \mathrm{dl}$ at 4 years, $4.2 \mathrm{~g} / \mathrm{dl}$ at 5 years, and $4.3 \mathrm{~g} / \mathrm{dl}$ at 6 years. The mean albumin levels for patients who received BPD-LL were $4.3 \mathrm{~g} / \mathrm{dl}$ at 1 year, $4.4 \mathrm{~g} / \mathrm{dl}$ at 2 years, $4.4 \mathrm{~g} / \mathrm{dl}$ at 3 years, $4.0 \mathrm{~g} / \mathrm{dl}$ at 4 years, $4.4 \mathrm{~g} / \mathrm{dl}$ at 5 years, and $4.3 \mathrm{~g} / \mathrm{dl}$ at 6 years. Albumin levels in the BPD-LL group were significantly lower than in the other groups $(p<0.05)$ at the 4-year follow-up.

Interestingly, in our cohort, hypoalbuminaemia defined as albumin $<3.5 \mathrm{~g} / \mathrm{dl}$ - was more frequently present in the RYGB $(3.2 \%$ at 1 year, $3.0 \%$ at 2 years, $6.3 \%$ at 3 years, and $4.3 \%$ at 5 years) and BPD-LL $(2.9 \%$ at 1 year, $3.0 \%$ at 2 years, and $5.9 \%$ at 3 years) groups than in the OAGB group $(2.9 \%$ at 4 years and $3.3 \%$ at 5 years). In any case, the deficiency was mild with the lowest value of albumin recorded being $3.1 \mathrm{~g} / \mathrm{dl}$. No patient required revision of the operation or total

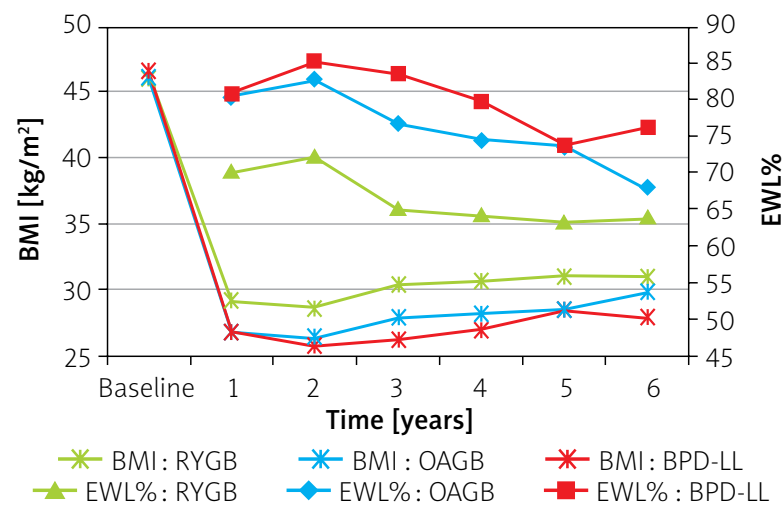

Figure 5. Efficacy of the procedures parenteral nutrition, and after nutritional counselling, hypoalbuminaemia did not recur.

\section{Efficacy and weight loss}

Mean excess weight loss (EWL\%) was $70.1 \%$ at 1 year, $72.3 \%$ at 2 years, $64.9 \%$ at 3 years, $64.2 \%$ at 4 years, $63.2 \%$ at 5 years, and $63.8 \%$ at 6 years for the RYGB group; $80.4 \%$ at 1 year, $82.6 \%$ at 2 years, $76.6 \%$ at 3 years, $74.5 \%$ at 4 years, $73.6 \%$ at 5 years, and $68.0 \%$ at 6 years for the OAGB group; and $80.9 \%$ at 1 year, $85.3 \%$ at 2 years, $83.6 \%$ at 3 years, $79.9 \%$ at 4 years, $73.8 \%$ at 5 years, and $76.3 \%$ at 6 years for the BPD-LL group. The mean EWL\% was always significantly greater, and the postoperative BMI was significantly lower after OAGB or BPD-LL compared to RYGB during the first 4 years ( $p<$ 0.001 in all cases). In subsequent years this effect was still evident, but its statistical significance was lost, perhaps due to a fall in the follow-up rate (Figure 5).

There was a considerable weight-loss failure rate in the RYGB group, which was evident even from the first postoperative year and significant $(p<0.001)$ after the third year. The failure rate for the RYGB group was 3.2\% at 1 year, $6.1 \%$ at 2 years, $21.9 \%$ at 3 years, $23.5 \%$ at 4 years, $26.1 \%$ at 5 years, and $16.0 \%$ at 6 years. Among the patients of the OAGB group, failure was recorded in $3.2 \%$ at 3 years, $8.8 \%$ at 4 years, $6.7 \%$ at 5 years, and $11.1 \%$ at 6 years, while among the BPD-LL group failures were observed only in $14.3 \%$ of the patients at 5 years.

\section{Comorbidities}

In the RYGB group, 6 patients were being medically treated preoperatively for diabetes mellitus type 2 , 12 had dyslipidaemia, and 10 were being medically treated for hypertension. In the OAGB group, 6 patients were being treated preoperatively for diabetes mellitus type 2 , 11 had dyslipidaemia, and 7 were being treated for hypertension. In the BPD-LL group, 6 patients were being treated preoperatively for diabetes mellitus type 2, 12 had dyslipidaemia, and 7 were being treated for hypertension.

Comorbidities were successfully encountered with all procedures at comparable rates (Figure 6). Two patients in the BPD group were treated preoperatively with insulin. In all patients a complete remission of diabetes mellitus type 2 was observed, with no need for antidiabetic medication. However, OAGB offered better overall glycaemic control and lower glucated haemoglobin $\left(\mathrm{HbA}_{1 \mathrm{c}}\right)$ levels than $\mathrm{RYGB}$ and comparable results to BPD-LL (5.0\% vs. $5.4 \%$ vs. $5.4 \%$ at 1 year, $5.0 \%$ vs. $5.3 \%$ vs. $4.8 \%$ at 2 years, $5.4 \%$ vs. $5.5 \%$ vs. $4.9 \%$ at 3 years, $5.2 \%$ vs. $5.6 \%$ vs. $5.2 \%$ at 4 years, $5.2 \%$ vs. $5.6 \%$ vs. $5.0 \%$ at 5 years, $5.4 \%$ vs. $5.4 \%$ vs. $5.5 \%$ at 6 years, respectively), even though in the OAGB group the preop- 


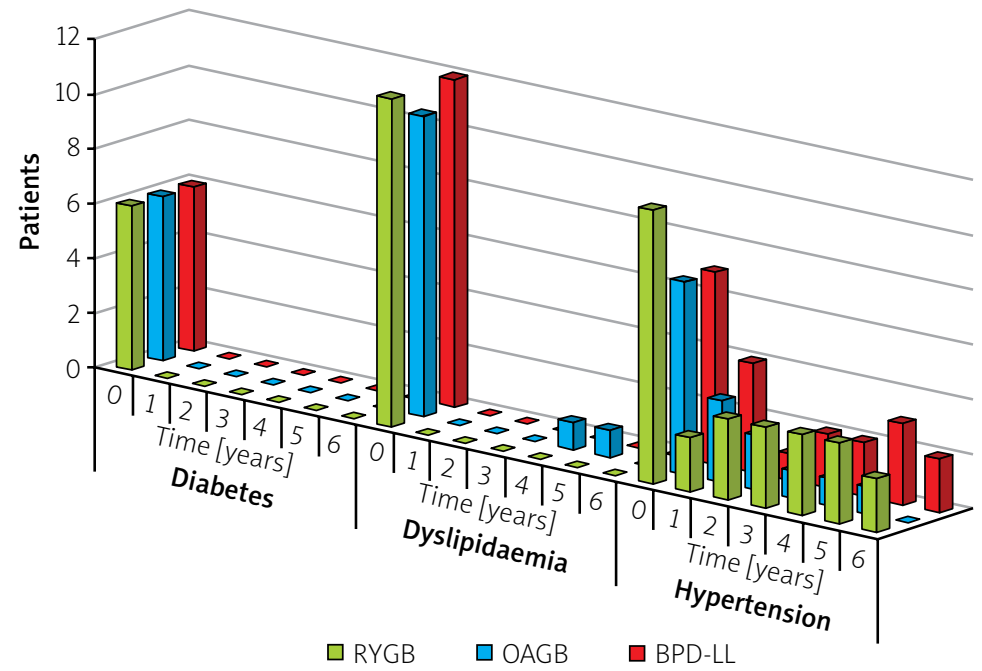

Figure 6. Resolution of comorbidities. Number of patients being treated for diabetes, dyslipidaemia, and hypertension

erative diabetes control was poorer (preoperative $\mathrm{HbA}_{1 \mathrm{c}}$ : RYGB: 6.6\% - OAGB: 7.7\% - BPD-LL: 7.5\%) (Figure 7).

Dyslipidaemia completely resolved in all BPD-LL and RYGB patients. Only one OAGB patient continued to be on statin therapy due to persistence of dyslipidaemia after the fourth year of the follow-up, although at lower doses than preoperatively.

Evolution of hypertension had worse consistency of findings. It was improved at the fifth year of follow-up in $70 \%$ (7 of the 10 ) RYGB patients, in $85.7 \%$ (6 of the 7 ) OAGB patients, and in $57.1 \%$ (4 of the 7 ) BPD-LL patients, with variations considering the time period. However, all patients continuing to be on anti-hypertensive treatment required lower doses in respect to those taken preoperatively.

\section{Discussion}

Malabsorptive procedures are considered to be the most effective procedures in terms of durable weight loss in patients with a $\mathrm{BMI}>50 \mathrm{~kg} / \mathrm{m}^{2}$. However, in patients with a BMI $<50 \mathrm{~kg} / \mathrm{m}^{2}$, there is no consensus regarding the appropriate bariatric procedure. RYGB is considered by some authors the gold standard in the treatment of morbidly obese patients with $\mathrm{BMI}<50 \mathrm{~kg} /$ $\mathrm{m}^{2}$, due to its acceptable efficiency and the low level of early and late complications $[10,15]$.

OAGB is a variation of gastric bypass, which has an established track record spanning many decades, and even procedures that came after it are now regarded as mainstream by most bariatric surgeons. Even though it has attracted a great deal of controversy, it is performed by an increasing number of bariatric surgeons worldwide due to its simplicity associated with a shorter learning curve, efficacy, and ease of revision and re-

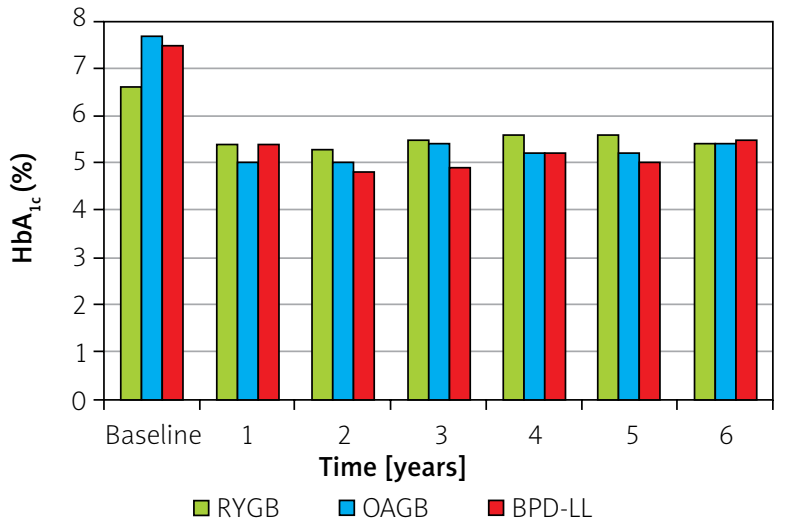

Figure 7. Glycaemic control of diabetic patients. $\mathrm{HbA}_{1 \mathrm{c}}$ for patients with preoperative DM

versal. The procedure has a reported low mortality rate of about $0.1 \%$. Complication rates are satisfactory, as are the results in terms of weight loss and comorbidity resolution [16].

$A$ recent systematic review provided evidence of good EWL outcomes with OAGB operation, with at least $68 \%$ at 5 years (mean $76.6 \%$ ), and numbers exceeding $90 \%$ have been reported [16]. Musella et al. and Taha et al. documented weight regain results of $0.2 \%$ and $1.2 \%$, respectively $[17,18]$. The mean weight regain in these patients was $12.6 \%$ from the maximum EWL. In another study [19], weight regain was reported in $12.9 \%$ of patients, with a mean weight regain of $6.18 \pm 3.76 \%$. These results are comparable with BPD-LL, which has a reported 5-year EWL of $74.6 \%$ in a non-superobese population, and is known to have the most sustainable in time bariatric outcomes [11]. The mean EWL achieved with RYGB at 5 years is lower; in recent studies it was reported at $57-65.7 \%$ [20-22]. Weight regain is com- 
mon after this procedure; Brissman et al. reported that $23.1 \%$ of cases met the definition of surgical treatment failure at 5 years [23]. Our results are consistent with these published data. At 5 years, mean EWL was $63.2 \%$ with RYGB, $73.6 \%$ with OAGB, and $73.8 \%$ with BPD-LL. Cases of weight regain were also observed. There was an $11.1 \%$ mid-term failure rate with OAGB, but this was significantly lower than the $26.1 \%$ with RYGB and comparable to the BPD-LL procedure.

Parmar et al. found in their review a mean T2DM remission rate of $83.7 \%$ and hypertension remission in $66.9 \%$ of patients with OAGB [16]. Piazza et al. reported resolution of dyslipidaemia in $70 \%$ of patients [24], while others showed that OAGB seems to be superior to standard restrictive procedures $[25,26]$. These numbers are comparable to our study.

Early major complications are reported in the literature from large series with a mean of about $1.3 \%$ and a maximum of $5.5 \%$, which included intra-abdominal bleeding, leaks, and early small bowel obstruction [16] In our cohort, we did not have any major complications in any group, but the small number of patients in each group is a limitation due to the small statistical power to identify complications with low incidence.

Some cases of stenosis of the GJ anastomosis were reported in the literature. Carbajo et al. presented a rate of $0.5 \%$; the majority of the patients were treated with endoscopic dilatation [27]. The authors concluded that increasing the anastomotic size from $1.5-2.0 \mathrm{~cm}$ to around $2.5 \mathrm{~cm}$ resolved this problem. There was no incidence of anastomotic stenosis in our cohort, neither in the OAGB or BPD-LL groups nor in the RYGB group, where the GJ anastomosis was narrower at $1.5 \mathrm{~cm}$.

None of the authors until now have reported closure of Petersen's defect in OAGB. Isolated case reports of internal hernia have been published [28], at 12 and 18 months after OAGB, both complicated with excess weight loss of about $132 \%$. These cases did not need bowel resection because there was no bowel ischaemia. More long-term data are needed in this field. Our practice is also against primary closure of the Petersen's defect.

There is a reported incidence of gastro-oesophageal reflux disease (GERD) symptoms after $\operatorname{OAGB}[29,30]$. In their review, Parmar et al. showed postoperative de novo GERD symptoms in 0.6 to $10 \%$ of patients, with a mean of $2.08 \%$ [16]. Tolone et al. in their study concluded that OAGB did not compromise the gastro-oesophageal junction function and did not increase gastro-oesophageal reflux [31]. It has been suggested that there may be an inverse correlation between the length of the gastric pouch and the incidence of GERD. Musella et al. observed that postoperative GERD after OAGB was related to the presence of preoperative GERD and to a gastric pouch length of less than $9.0 \mathrm{~cm}$ [32]. The maximum conversion rate reported in the literature due to GERD is $1.6 \%$ in the study of Chevallier et al. after a 5-year follow-up, but most of the cases described were managed conservatively with healthy life recommendations, PPI, and sucralfate [33].

The major concern about this operation is the possibility of alkaline oesophagitis following bile reflux. However, in a study of by Saarinen et al., by means of bile reflux scintigraphy it was shown that transient bile reflux is common after OAGB in the gastric tube, but not in the oesophagus [34]. This can also be attributed to the long and narrow shape of the gastric pouch.

Intolerance due to bile reflux was reported on average in $0.3 \%$ of patients, with various approaches used for its treatment. Piazza et al. performed a Braun's anastomosis at $40 \mathrm{~cm}$ from the GJ anastomosis for those patients (1\%) who required revision [24]. Noun et al. had $4(0.4 \%)$ patients, all with OAGB after revisional surgery, who presented with severe bile reflux; these were cured by stapling the afferent loop followed by a distal jejuno-jejunostomy $70 \mathrm{~cm}$ distal to the $\mathrm{G}$ J anastomosis [19]. We also believe that if any revisional operation is needed for GERD of reflux, the patients will have achieved significant EWL and co-morbidity improvement, and hence the revision will be technically easier and effective.

However, no case of clinically significant postoperative GERD or bile reflux was observed in our study. Some patients reported GERD randomly at some time in the follow-up, but it was not consistent during the period of the study and did not require medication. It was not possible to be correlated with any specific procedure. This may be attributed to the mechanism of action of RYGB and BPD-LL, which are known to treat GERD due to the isolated long alimentary limb [35], as well as to the relatively small number of patients in the OAGB group that does not provide enough power to identify complications with low incidence. The majority of surgeons who do not perform OAGB continue to believe that this procedure could be associated with a higher risk of gastric and/or oesophageal cancer [36]. This is despite the fact that not a single cancer has yet been reported in the oesophagus or gastric pouch after this procedure [16]. Only one case of gastric cancer, in the remnant stomach, 9 years after OAGB, has been reported in the literature, while 7 similar cases have been reported in the bypassed stomach after RYGB [37].

A marginal ulcer rate was reported in the review by Parmar et al. at a mean of $2.7 \%$, which is similar to that reported after RYGB [16]. The majority of the patients had risk factors such as the presence of Helicobacter 
pylori and consumption of nonsteroid anti-inflammatory drugs (NSAID) medications, alcohol, and tobacco. Most of these ulcers heal with conservative management, and complications of ulcers, such as perforation, bleeding, and non-healing ulcers, can be managed in the same way as after RYGB [38]. BPD-LL is related to a slightly higher risk of marginal ulcer than the other procedures, due to higher acidity of the bigger gastric pouch [13]. No cases of marginal ulcer were observed in our cohort.

Nutritional consequences, including anaemia, occur after bariatric operations, including OAGB. In the review by Parmar et al., anaemia was observed in 0.64 to $15 \%$ of cases, with a mean of $7 \%$, among all published series [16]. Lee, in his comparison of OAGB with RYGB [39], concluded that both procedures were associated with a decrease in haemoglobin, but OAGB patients presented with a lower value, compared to RYGB $(10.1 \pm 2.8 \mathrm{vs}$. $12.5 \pm 1.4 ; p=0.006$ ). In the literature, severe iron deficiency (requiring parenteral iron supplementation) is reported at rate of up to $1.25 \%$, and mild iron deficiency (needing oral iron) at a rate of up to 30\% [40]. Mokhber et al. observed that the prevalence of iron deficiency was $15 \%$ preoperatively, which increased to $16.6 \%$ at 3 months and $21.5 \%$ at 6 months postoperatively [41]. In the present study, anaemia was observed only in women, and was not comparable with previously reported rates. However, in this population OAGB as well as BPD-LL correlate with anaemia more frequently than RYGB; therefore, patients should be closely monitored. There were 2 cases requiring intravenous iron administration; both were observed in the more malabsorptive groups of the cohort (OAGB and BPD-LL).

Protein-calorie malnutrition requiring revisional surgery is another debated long-term complication after OAGB. The majority of published series report $0 \%$ malnutrition, while Parmar et al. [16] reported a malnutrition incidence of 0 to $3.8 \%$ with a mean of $0.71 \%$. There are higher rates reported in the literature; Jammu et al. reported an incidence of hypoalbuminaemia of $13.1 \%$, of which $3.8 \%$ of patients had severe hypoalbuminaemia $(<2.5 \mathrm{~g} / \mathrm{dl})$ and $9.3 \%$ had mild hypoalbuminaemia (3.0-2.5 g/dl) [42]. Severe hypoalbuminaemia was treated by reversal of OAGB. It is suggested that in patients with liver disease, small intestine length of $<8 \mathrm{~m}$, and nephropathy, surgeons should avoid limb length of $>200 \mathrm{~cm}$. However, BPD is well associated with protein malnutrition at rates usually around $7 \%$ and severe hypoalbuminaemia requiring total parenteral nutrition [13].

It seems obvious that there is a correlation between the length of the bilio-pancreatic (BP) limb and the incidence of malnutrition. There have been considerable variations in bilio-pancreatic limb length in published studies of OAGB. The median limb length in the most recent review was $200 \mathrm{~cm}$ [16]. Rutledge first described MGB with a biliopancreatic limb length of $180 \mathrm{~cm}$ [5]. Carbajo et al. used $200 \mathrm{~cm}$ for their first 200 patients; later they measured the whole small bowel length and used a segment of 250 to $350 \mathrm{~cm}$ [27]. Many authors tailored the limb length based on the BMI of the patient, usually at the range $200-250 \mathrm{~cm}$ [16]. Piazza et al. used $180-200 \mathrm{~cm}$ as a routine and $240 \mathrm{~cm}$ for 7 patients with a BMI of $59.4 \mathrm{~kg} / \mathrm{m}^{2}$ [24]. Mahawar [43] suggested that malnutrition complications can be completely prevented by using a standard limb length of $150 \mathrm{~cm}$ with OAGB; there is still no study designed to investigate this. Meanwhile, the patients should have robust follow-up with monitoring of micronutrients, minerals, and vitamins.

In our study, the length of the bypassed limb in OAGB was $250 \mathrm{~cm}$. We observed only mild cases of hypoalbuminaemia; the rate was double with BPD-LL compared to RYGB and OAGB.

No patient required revision of the operation or total parenteral nutrition, and after nutritional consultation, hypoalbuminaemia did not recur. This could be attributed to the length of the alimentary and common channel, which always exceeded $300 \mathrm{~cm}$, in all types of operations.

There seems to be an additional impact for calcium levels for OAGB patients comparing to other, even more malabsorptive procedures like BPD-LL. With the postoperative calcium and vitamin $D_{3}$ supplementation currently used in our study, RYGB patients sometimes had higher calcium levels than preoperatively, and the prevalence of SHPT decreased. The same doses were insufficient for the more malabsorptive procedures, with OAGB patients having significantly lower calcium levels in the long term. Although calcium deficiency can be aggravated by vitamin $D_{3}$ deficiency, secondary hyperparathyroidism is is found even in around half of the patients who have normal levels of vitamin $D_{3}$ after malabsorptive procedures [44, 45]. Individual differences in active and/or passive calcium absorption may account for these findings. In our cohort the prevalence of SHPT increased continually in the long run postoperatively, although the rates in our study are lower than those published by other authors [4648]. Unfortunately, inconsistencies of our laboratory measurements of vitamin $D_{3}$ due to technical reasons prevent a further evaluation of the correlation between the degree of iatrogenic malabsorption and the incidence of SHPT, and further studies are required. However, it is important to ensure a sufficient calcium intake in OAGB patients in order to avoid SHPT and osteomalacia in the future. 
Folic acid deficiency is a potential complication of bariatric procedures that can contribute to anaemia. The prevalence of this deficit after both restrictive and malabsorptive procedures ranges from $9 \%$ to $39 \%[49,50]$. Because folate is absorbed throughout the small intestine, any deficiency is primarily induced by a shortage of dietary intake rather than malabsorption [51]. In our study, there was an unexpected significant increase in the mean levels of folic acid in the BPD-LL group in comparison with the RYGB and OAGB groups. This may be attributed to increased dietary uptake or increased compliance with multi-vitamin medication, as a result of BPD-LL patients' awareness about the extremely malabsorptive nature of their procedure.

There are some weaknesses to our study. Despite strictly monitoring our patients, follow-up rates dropped in the last 2 years. The relatively small number of patients in each group limits the statistical power of the study to outline small differences; however, the data collected are consistent with the literature.

\section{Conclusions}

Biliopancreatic diversions were shown to provide the higher and most sustainable weight loss and the most powerful effect in controlling blood glucose levels and lipid levels. However, they always have the possibility to cause nutritional deficiencies. While none of the patients in this cohort required revision for hypoalbuminaemia or hospital admission, albumin levels were significantly lower in the BPD-LL group, and some patients required nutritional consultation. There seems to be an additional impact on calcium levels for OAGB patients compared to other procedures. The finding requires further investigation; in any case, we suggest that patients have a more robust follow-up to check for the development of secondary hyperparathyroidism.

From our perspective, the study provides adequate results in support of the opinion that OAGB offers comparable mid-term results as the BPD-LL procedure, which is regarded as the most effective, while being significantly safer - at the level of RYGB - with minimal impact on patients' nutritional state. It could also be an efficient alternative to RYGB because it is easier to perform or revise and has significantly lower failure rates. It is an effective procedure in treating morbid obesity and metabolic disorders, which results in sustained weight loss and high rates of resolution of comorbidities.

\section{Conflict of interest}

The authors declare no conflict of interest.

\section{References}

1. Maggard MA, Shugarman LR, Suttorp M, et al. Metaanalysis: surgical treatment of obesity. Ann Intern Med 2005; 142: 547-59.

2. Buchwald $\mathrm{H}$. Overview of bariatric surgery. J Am Coll Surg 2002; 194: 367-75.

3. Pournaras DJ, Aasheim ET, Bueter M, et al. Effect of bypassing the proximal gut hormones involved with glycemic control and weight loss. Surg Obes Relat Dis 2012; 8: 371-4.

4. Chronaiou A, Tsoli M, Kehagias I, et al. Lower ghrelin levels and exaggerated postprandial peptide-YY, glucagon-like peptide- 1 and insulin responses, after gastric fundus resection, in patients undergoing Roux-en-Y gastric bypass: a randomized clinical trial. Obes Surg 2012; 22: 1761-70.

5. Rutledge R, Walsh TR. Continued excellent results with the minigastric bypass: six-year study in 2,410 patients. Obes Surg 2005; 15: 1304-8.

6. Lee WJ, Lin YH. Single-anastomosis gastric bypass (SAGB): appraisal of clinical evidence. Obes Surg 2014; 24: 1749-56.

7. De Luca M, Tie T, Ooi G, et al. Mini gastric bypass-one anastomosis gastric bypass (MGB-OAGB)-IFSO position statement. Obes Surg 2018; 28: 1188-206.

8. Marceau P, Biron S, Hould FS, et al. Malabsorption procedure in surgical treatment of morbid obesity. Probl Gen Surg 2000; 17: 29-39.

9. Brolin RE, LaMarca LB, Kenler HA, et al. Malabsorptive gastric bypass in patients with superobesity. J Gastrointest Surg 2002; 6: 195-203.

10. Brolin RE, Leung M. Survey of vitamin and mineral supplementation after gastric bypass and biliopancreatic diversion for morbid obesity. Obes Surg 1999; 9: 150-4.

11. Skroubis G, Kouri N, Mead N, Kalfarentzos F. Long-term results of a prospective comparison of Roux-en-Y gastric bypass versus a variant of biliopancreatic diversion in a non-superobese population (BMI 35-50 kg/m2). Obes Surg 2014; 24: 197-204.

12. Alexandrides TK, Skroubis G, Kalfarentzos F. Resolution of diabetes mellitus and metabolic syndrome following Roux-en-Y gastric bypass and a variant of biliopancreatic diversion in patients with morbid obesity. Obes Surg 2007; 17: 176-84.

13. Kalfarentzos F, Skroubis G, Karamanakos S, et al. Biliopancreatic diversion with Roux-en-Y gastric bypass and long limbs: advances in surgical treatment for super-obesity. Obes Surg 2011; 21: 1849-58.

14. Skroubis G, Sakellaropoulos G, Pouggouras K, et al. Comparison of nutritional deficiencies after Roux-en-Y gastric bypass and after biliopancreatic diversion with Roux-en-Y gastric bypass. Obes Surg 2002; 12: 551-8.

15. Buchwald H. A bariatric surgery algorithm. Obes Surg 2002; 12: 733-46.

16. Parmar CD, Mahawar KK. One Anastomosis (mini) gastric bypass is now an established bariatric procedure: a systematic review of 12,807 patients. Obes Surg 2018; 28: 2956-67.

17. Musella M, Susa A, Greco F, et al. The laparoscopic mini-gastric bypass: the Italian experience: outcomes from 974 consecutive cases in a multicenter review. Surg Endosc 2014; 28: 156-63.

18. Taha O, Abdelaal M, Abozeid M, et al. Outcomes of omega loop gastric bypass, 6-years' experience of 1520 cases. Obes Surg 2017; 27: 1952-60. 
19. Noun R, Skaff J, Riachi E, et al. One thousand consecutive minigastric bypass: short- and long-term outcome. Obes Surg 2012; 22: 697-703.

20. Sharples AJ, Mahawar K. Systematic review and meta-analysis of randomised controlled trials comparing long-term outcomes of Roux-En-Y gastric bypass and sleeve gastrectomy. Obes Surg 2020; 30: 664-72.

21. Ismail M, Nagaraj D, Rajagopal $M$, et al. Is weight regaining sig nificant post laparoscopic Roux-en-Y gastric bypass surgery? A 5-year follow-up study on Indian patients. J Minim Access Surg 2021; 17: 159-64.

22. Salminen P, Helmiö M, Ovaska J, et al. Effect of laparoscopic sleeve gastrectomy vs laparoscopic Roux-en-Y Gastric bypass on weight loss at 5 years among patients with morbid obesity: the SLEEVEPASS randomized clinical trial. JAMA 2018; 319 . 241-54.

23. Brissman M, Beamish AJ, Olbers T, Marcus C. Prevalence of insufficient weight loss 5 years after Roux-en- $Y$ gastric bypass: metabolic consequences and prediction estimates: a prospective registry study. BMJ Open 2021; 11: e046407.

24. Piazza L, Ferrara F, Leanza S, et al. Laparoscopic mini-gastric bypass: short-term single-institute experience. Update Surg 2011; 63: 239-42.

25. Lee WJ, Chong K, Lin YH, et al. Laparoscopic sleeve gastrectomy versus single anastomosis (mini-) gastric bypass for the treatment of type 2 diabetes mellitus: 5-year results of a randomized trial and study of incretin effect. Obes Surg 2014; 24: 1552-62.

26. Musella M, Apers J, Rheinwalt K, et al. Efficacy of bariatric surgeryin type 2 diabetes mellitus remission: the role of mini gastric bypass/one anastomosis gastric bypass and sleeve gastrectomy at 1 year of follow-up. A European survey. Obes Surg 2016; 26: 933-40.

27. Carbajo MA, Luque-de-León E, Jiménez JM, et al. Laparoscopic one-anastomosis gastric bypass: technique, results, and long-term follow-up in 1200 patients. Obes Surg 2017; 275 1153-67.

28. Facchiano E, lannelli A, Lucchese M. Internal hernia after minigastric bypass: myth or reality? J Visc Surg 2016; 153: 231-2.

29. Kular KS, Manchanda N, Rutledge R. A 6-year experience with 1,054 mini-gastric bypasses-first study from Indian subcontinent. Obes Surg 2014; 24: 1430-5.

30. Parmar CD, Mahawar KK, BoyleM, et al. Mini gastric bypass: first report of 125 consecutive cases from United Kingdom. Clin Obes 2016; 6: 61-7.

31. Tolone S, Cristiano S, Savarino E, et al. Effects of omega-loop bypass on esophagogastric junction function. Surg Obes Relat Dis 2016; 12: 62-9.

32. Musella M, Susa A, Manno E, et al. Complications following the mini/one anastomosis gastric bypass (MGB/OAGB): a multiinstitutional survey on 2678 patients with a mid-term (5 years) follow-up. Obes Surg 2017; 27: 2956-67.

33. Chevallier JM, Arman GA, Guenzi M, et al. One thousand single anastomosis (omega loop) gastric bypasses to treat morbid obesityin a 7-year period: outcomes show few complications and good efficacy. Obes Surg 2015; 25: 951-8.

34. Saarinen T, Räsänen J, Salo J, et al. Bile reflux scintigraphy after mini-gastric bypass. Obes Surg 2017; 27: 2083-9.
35. Bevilacqua LA, Obeid NR, Yang J, et al. Incidence of GERD, esophagitis, Barrett's esophagus, and esophageal adenocarcinoma after bariatric surgery. Surg Obes Relat Dis 2020; 16 : 1828-36.

36. Mahawar KK, Borg CM, Kular KS, et al. Understanding objections to one anastomosis (mini) gastric bypass: a survey of 417 surgeons not performing this procedure. Obes Surg 2017; 27: 2222-8

37. Wu CC, Lee WJ, Ser KH, et al. Gastric cancer after mini-gastric bypass surgery: a case report and literature review. Asian J Endosc Surg 2013; 6: 303-6.

38. Mahawar KK, Reed AN, Graham YNH. Marginal ulcers after one anastomosis (mini) gastric bypass: a survey of surgeons. Clin Obes 2017; 7: 151-6.

39. Lee WJ, Ser KH, Lee YC, et al. Laparoscopic Roux-en-Y vs. mini-gastric bypass for the treatment of morbid obesity: a 10year experience. Obes Surg 2012; 22: 1827-34

40. Carbajo MA, Luque-de-León E, Jiménez JM, et al. Laparoscopic one-anastomosis gastric bypass: technique, results, and longterm follow-up in 1200 patients. Obes Surg 2017; 27: 1153-67.

41. Mokhber S, Nikoyan P, Kabir A, et al. Anaemia outcome after laparoscopic mini bypass: analysis of 107 consecutive patients. Acta Gastroenterol Belg 2016; 79: 201-5.

42. Jammu GS, Sharma R. A 7-year clinical audit of 1107 cases comparing sleeve gastrectomy, Roux-en-Y gastric bypass, and minigastric bypass, to determine an effective and safe bariatric and metabolic procedure. Obes Surg 2016; 26: 926-32.

43. Mahawar K. A biliopancreatic limb of $>150 \mathrm{~cm}$ with OAGB/ MGB is ill-advised. Obes Surg 2017; 27: 2164-5.

44. Wei JH, Lee WJ, Chong K, et al. High incidence of secondary hyperparathyroidism in bariatric patients: comparing different procedures. Obes Surg 2018; 28: 798-804.

45. Switzer NJ, Marcil G, Prasad S, et al. Long-term hypovitaminosis D and secondary hyperparathyroidism outcomes of the Roux-en-Y gastric bypass: a systematic review. Obes Rev 2017; 18: 560-6.

46. Alejo Ramos M, Cano Rodríguez IM, Urioste Fondo AM, et al. Secondary hyperparathyroidism in patients with biliopancreatic diversion after 10 years of follow-up, and relationship with vitamin D and serum calcium. Obes Surg 2019; 29: 999-1006.

47. White MG, Ward MA, Applewhite MK, et al. Rates of secondary hyperparathyroidism after bypass operation for super-morbid obesity: an overlooked phenomenon. Surgery 2017; 161: 720-6.

48. Balsa JA, Botella-Carretero J, Peromingo R, et al. Role of calcium malabsorption in the development of secondary hyperparathyroidism after biliopancreatic diversion. J Endocrinol Invest 2008; 31: 845-50.

49. von Drygalski A, Andris DA, Nuttleman PR, et al. Anemia after bariatric surgery cannot be explained by iron deficiency alone: results of a large cohort study. Surg Obes Relat Dis 2011; 7: 151-6.

50. Shankar P, Boylan M, Sriram K. Micronutrient deficiencies after bariatric surgery. Nutrition 2010; 26: 1031-7.

51. Lupoli R, Lembo E, Saldalamacchia G, et al. Bariatric surgery and long-term nutritional issues. World J Diabetes 2017; 8: 464-74.

Received: 5.06.2021

Accepted: 21.06 .2021 